\title{
Análisis de residuos orgánicos y microfósiles silíceos de la "cuchara" de cerámica del sitio arqueológico Cerro Tapera Vázquez (Parque Nacional Pre-Delta, Argentina)
}

\author{
Mariano Bonomo* \\ Milagros Colobig** \\ Natalia Mazzi***
}

BONOMO, M.; COLOBIG, M.; MAZZIA, N. Análisis de residuos orgánicos y microfósiles silíceos de la "cuchara" de cerámica del sitio arqueológico Cerro Tapera Vázquez (Parque Nacional Pre-Delta, Argentina). R. Museu Arq. Etn., São Paulo, n. 22: 31-50, 2012.

Resumen: El objetivo del presente artículo es establecer la función de una cuchara de cerámica hallada en el sitio arqueológico Cerro Tapera Vázquez, Pre-Delta del río Paraná (Argentina). Para ello se estudiaron los residuos adheridos a su superficie interna a través de análisis de ácidos grasos, microfósiles silíceos y almidones. Paralelamente, se consideraron sus atributos morfológicos, tamaño y alteraciones por uso, que fueron comparadas con los de otras cucharas de cerámica relevadas en colecciones de la región. La información obtenida en cuanto a la forma abierta del pequeño contenedor cerámico, el delgado espesor de sus paredes, los residuos identificados, la concentración de humedad en su interior y tubo lateral y las evidencias de exposición al fuego en la mayor parte de la superficie externa, permite proponer que la cuchara sirvió para calentar y beber líquidos hechos a base de vegetales.

Palabras clave: Ácidos grasos, Fitolitos, Almidones, Delta del Paraná, Holoceno tardío

\section{Introducción}

$\mathrm{N}$ umerosos estudios arqueológicos y etnoarqueológicos realizados desde fines de la década de 1970 (DeBoer y Lathrap 1979; Hally
1983, 1986; Rice 1987; Skibo 1992; Kobayashi 1994; Menacho 2007; Boudreaux 2010, entre otros) han aportado importante información analógica, desarrollado estrategias metodológicas e identificado las principales variables para analizar

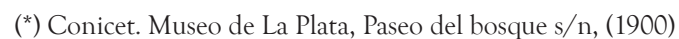
La Plata, provincia de Buenos Aires, Argentina.<mbonomo@ fcnym.unlp.edu.ar>

${ }^{* *}$ Conicet. Laboratorio de Paleobotánica. Centro de Investigaciones Científicas y Transferencia de Tecnología a la
Producción, Dr. Materi y España s/n, (E3105BWA) Diamante, provincia de Entre Ríos, Argentina. <mcolobig@cicyttp.org.ar> $\left({ }^{* *}\right)$ Conicet. Área Arqueología y Antropología, Municipalidad de Necochea, Av. 10 y calle 63 s/nº, (7630) Necochea, provincia de Buenos Aires, Argentina. <natymazzia@yahoo.com.ar> 
Análisis de residuos orgánicos y microfósiles silíceos de la "cuchara" de cerámica del sitio arqueológico Cerro Tapera Vázquez (Parque Nacional Pre-Delta, Argentina)

R. Museu Arq. Etn., São Paulo, n. 22: 31-50, 2012.

la función de los recipientes cerámicos. Estas investigaciones se han basado en la morfología, tamaño y decoración de las vasijas, la composición de las pastas y antiplásticos empleados, el contexto de asociación de las piezas, las alteraciones macroscópicas de las superficies y las sustancias adheridas durante su uso.

Entre la alfarería hallada en los sitios arqueológicos de la llanura aluvial del río Paraná Medio e Inferior en Argentina se han registrado en baja frecuencia pequeños recipientes abiertos, poco profundos, de forma oval y con un tubo que sale en ángulo recto de un lateral (Serrano 1934: lámina VII, 1950: fig. 27, 39; Gaspary 1950: fig. 38). Estas piezas han sido llamadas de forma genérica "cucharas" y se han atribuido a lo que actualmente se conoce como entidad arqueológica Goya-Malabrigo (2000-300 años C14 BP) (Ceruti 1993, 2003; véase discusión en Politis y Bonomo 2012). Antonio Serrano (1950) ha vinculado el tubo que poseen en el borde con el pasaje de líquidos y, específicamente, ha sostenido que podrían ser picos para recipientes hechos de cuero u odres. Sin embargo, a pesar de este vínculo entre forma y función y de su denominación local como "cucharas", sus usos son aún desconocidos. Hasta el presente no se han obtenido evidencias arqueológicas, ni discutido ejemplos etnográficos que ayuden a comprender para qué fueron utilizadas.

El objetivo de este trabajo es establecer la función para la cual fue utilizada una de estas cucharas de cerámica recuperada en el sitio arqueológico Cerro Tapera Vázquez (Bonomo et al. 2011a) localizado en el Pre-Delta del río Paraná (Fig. 1). Para ello se analizaron atributos de la forma, tamaño y alteraciones por uso, conjuntamente con los ácidos grasos y restos botánicos adheridos y adsorbidos en la superficie interna de la pieza a los efectos de evaluar qué tipo de sustancias pudo haber contenido este recipiente. Estos estudios apuntan a obtener evidencias independientes acerca de los usos de la cuchara, empleando distintas vías analíticas que se complementan con el fin de poder evaluar la coherencia de los resultados alcanzados. Desde un enfoque arqueométrico se estudiaron los residuos químicos por medio de cromatografía gaseosa-espectrometría de masas (CG-EM). En tanto que desde una perspectiva paleoetnobotánica, se analizaron e identificaron mediante microscopía óptica los fitolitos y almidones de las superficies interna y externa de la pieza.

Los análisis de residuos químicos se efectúan sobre una pequeña muestra de grasa que ha quedado atrapada durante su uso en las porosidades de los objetos arqueológicos. Las grasas o lípidos presentes en los tejidos animales y vegetales están compuestas por átomos de Carbono e Hidrógeno y en menor proporción de Oxígeno. Algunas de las particularidades de este conjunto de moléculas orgánicas es que son hidrofóbicas o insolubles en agua, muestran una gran estabilidad frente a altas temperaturas y una descomposición mínima a través del tiempo en condiciones ambientales constantes (Feiser y Feiser 1960; Rottländer 1990). De esta forma, los lípidos pueden sobrevivir adsorbidos en la pasta cerámica, permaneciendo en micro-oquedades que inhiben el acceso a microorganismos por su tamaño o por encontrarse selladas con residuos bacterianos. Además, gracias a su propiedad hidrofóbica no se produce la pérdida de estas biomoléculas por el lavado de los materiales con agua (Evershead 1993). Dentro de este conjunto se incluyen los ácidos grasos, compuestos naturales de cadena lineal y con número par de átomos de Carbono en cada molécula (Fankhauser 1994). Además de la posibilidad de detectar grasas de origen animal y aceites vegetales, los análisis de ácidos grasos han permitido identificar alimentos específicos (p. ej. miel, cacao, harinas, leche y productos derivados), bebidas fermentadas, combustibles, resinas y pigmentos en el registro arqueológico (Evershed 2008).

Por su parte, el análisis de microfósiles en artefactos arqueológicos constituye otra vía, a veces la única, para registrar y recuperar evidencias directas del uso de vegetales, considerando que en numerosos ambientes las posibilidades de preservación de restos macroscópicos de plantas son muy acotadas (Torrence 2006; Yang y Jiang 2010). La combinación de la observación de microfósiles vegetales de diferente origen anatómico y/o fisiológico (granos de almidón, silicofitolitos, frústulas de diatomeas) o de origen animal (espículas de espongiarios) tienen un gran potencial 


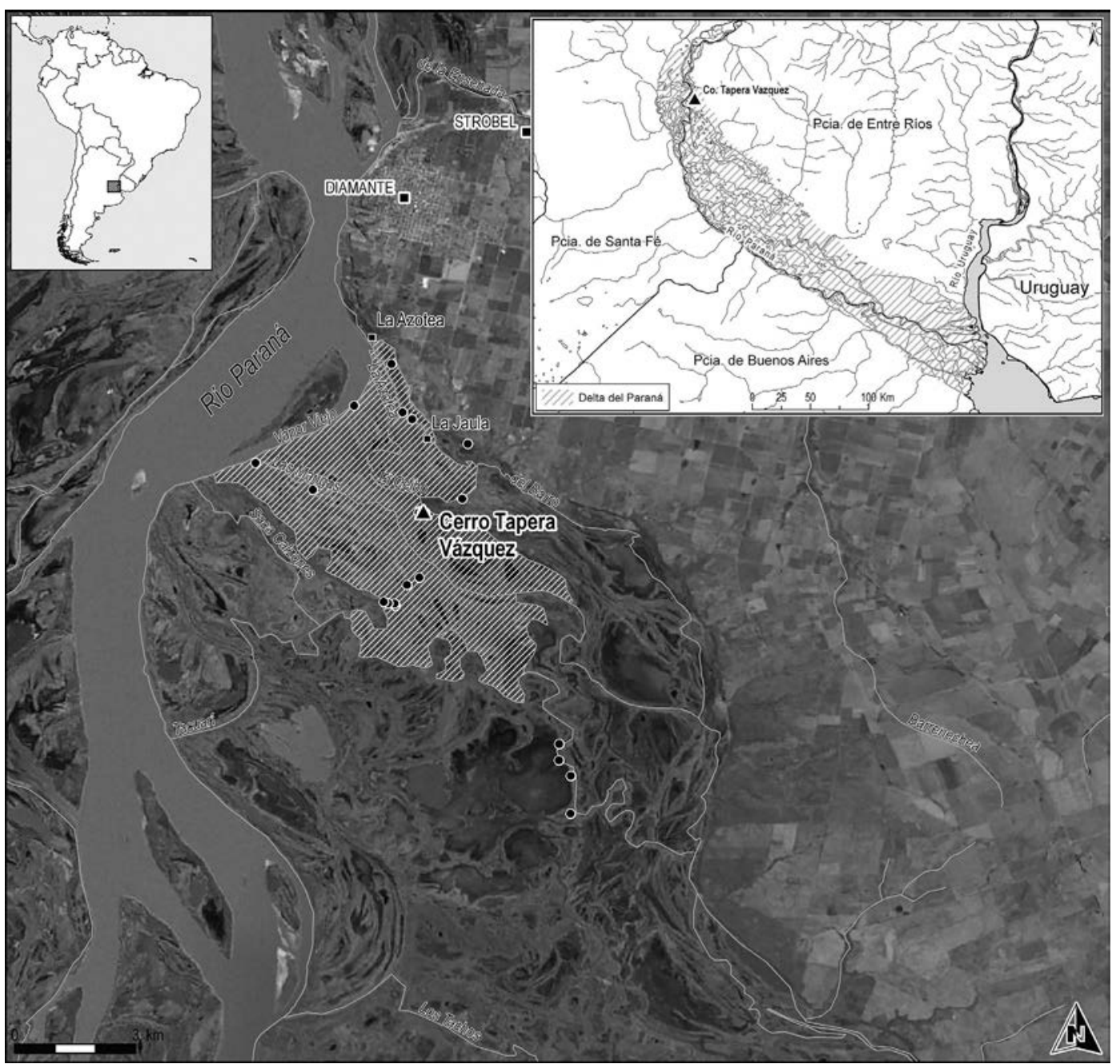

Fig. 1. Ubicación geográfica del sitio arqueológico Cerro Tapera Vázquez (Parque Nacional Pre-Delta).

para responder preguntas arqueológicas, como por ejemplo qué recursos fueron empleados por las poblaciones humanas en el pasado (véase $\mathrm{p}$. ej. Babot 2007). El valor taxonómico de cada uno de estos microfósiles es diferente, de acuerdo con la presencia en las muestras de formas diagnósticas como así también de las condiciones de preservación de cada microfósil. En términos generales, la identificación de los granos de almidón permite un mayor grado de especificidad para la determinación de las plantas utilizadas e indican procesos de manufactura, almacenamiento y procesamiento de alimentos (Zucol y Bonomo 2008; Zucol et al. 2008; Babot 2011) preservándose mejor en artefactos y sustancias adheridas que en sedimentos (Babot 2007).

Los fitolitos, en cambio, se preservan en muy variados depósitos y contextos. Aparecen vinculados al acondicionamiento de recintos y su sectorización y a la utilización de combustibles, mordientes o pigmentos de origen vegetal (Zucol et al. 2007; Korstanje y Cuenya 2008; Zucol y Bonomo 2008; Zucol et al. 2008; Colobig 2011; Colobig en prensa; Martínez et al. en prensa; Zucol et al. en prensa, entre otros). Esto se debe a que, por lo general, los fitolitos se acumulan en tejidos de protección y/o sostén, tales como inflorescencias y tallos (Piperno 
Análisis de residuos orgánicos y microfósiles silíceos de la "cuchara" de cerámica del sitio arqueológico Cerro Tapera Vázquez (Parque Nacional Pre-Delta, Argentina)

R. Museu Arq. Etn., São Paulo, n. 22: 31-50, 2012.

1988). Estos tejidos generalmente tienen escasa importancia como alimentos, a diferencia de los granos de almidón que se almacenan en altas cantidades en órganos de reserva con un alto valor nutritivo, como ocurre en tubérculos, raíces, semillas y frutos.

\section{Materiales y Métodos}

La cuchara de cerámica ( ${ }^{\circ}$ CTV.1.12.6) de Cerro Tapera Vázquez fue recuperada en la capa IV a los $164 \mathrm{~cm}$ de profundidad del nivel $0^{1}$ de la excavación, en el anteúltimo nivel con materiales arqueológicos de la cuadrícula 1 . Sobre esta pieza se realizaron análisis de residuos orgánicos y de microfósiles.

\section{Análisis de residuos orgánicos}

La cromatografía gaseosa permite la separación de mezclas de compuestos orgánicos volátiles o semivolátiles mediante el uso de protocolos y equipamientos específicos y la posterior interpretación de los cromatogramas (gráficos) resultantes. Esto último implica determinar el porcentaje de cada ácido graso en relación con el total existente en la muestra para, posteriormente, relacionar una propiedad química, como la presencia o ausencia de un compuesto particular o mezcla de compuestos, con las características de productos animales y vegetales contemporáneos tomados como referencia (Evershead et al. 1992).

Cabe destacar que existen ciertas limitaciones en cuanto a la interpretación de los resultados obtenidos. Los ácidos grasos pueden haber sufrido una alteración de las proporciones relativas originales debido a procesos como la oxidación que actúa bajo la influencia del Oxígeno, la humedad, enzimas y microorganismos (Evershead et al. 1992; Bondia Pons 2007). También es posible que se produzca cierto intercambio de lípidos con la matriz sedimentaria

(1) El nivel 0 del sitio arqueológico Cerro Tapera Vázquez está ubicado a entre 0,79 y $1,26 \mathrm{~m}$ de la superficie del terreno. donde se recuperaron las piezas arqueológicas. Debido a que los lípidos son parte constitutiva del medioambiente, cabe la posibilidad de que aquellos absorbidos a partir del sedimento circundante sean erróneamente interpretados como evidencias de recursos procesados con los artefactos arqueológicos (Buonasera 2007). Por este motivo, como recaudo metodológico, se realizó el análisis químico de los sedimentos arcillo-limosos de la capa IV, portadora de la pieza estudiada. A los efectos de examinar la posibilidad de migración de lípidos contenidos en la matriz sedimentaria en que se encontró la cuchara de cerámica, fue analizada una muestra de sedimento de esta capa en la cuadrícula 5.

Paralelamente, se extrajeron dos muestras de sustancias lipídicas de la superficie interna del contenedor de la cuchara utilizando dos métodos. Una de las muestras se obtuvo por raspado (10-090603), mientras que la otra por inmersión en solvente (10-090602). La extracción por raspado agrega, en este caso, mayor confiabilidad a las muestras obtenidas ya que se ha comprobado que cuando se trata de objetos manufacturados en cerámica, las sustancias permanecen protegidas en la matriz estando menos expuestas a procesos de descomposición y contaminación (Rottländer 1990; Skibo y Deal 1995). Ambos muestreos se tomaron de la misma sección de la pieza con la finalidad de obtener resultados comparables.

Las muestras fueron preparadas con cloroformo-metanol (2:1), luego con trifloururo de boro en metanol y hexano; los extractos fueron filtrados y concentrados con Nitrógeno para ser inyectados en el equipo CG-EM ${ }^{2}$ en un volumen de 0,2 microlitros. Cada uno de los espectros obtenidos fue comparado con bases de datos de referencia y bibliografía específica sobre el tema (p. ej. Robinson et al. 1991; Fankhauser 1994; Craig et al. 2005; Buenasera 2007).

(2) El equipo empleado fue un sistema cromatógrafo gaseosoespectrómetro de masa Shimadzu QP-5000. Para el análisis de las muestras se trabajó con una columna capilar RXL-5MS de $30 \mathrm{~m}$ y un diámetro de $0,25 \mathrm{~mm}$. La temperatura del inyector fue de $240^{\circ} \mathrm{C}$. 


\section{Análisis de microfósiles}

Las muestras para el análisis de microfósiles se tomaron por raspado en seco, obteniéndose tres tipos de muestras: M1 (superficie basal interna del contenedor); M2 (superficie interna del tubo) y M3 (superficie externa ennegrecida). Para la concentración de los granos de almidón se adaptó la metodología propuesta por Pearsall et al. (2004) y Horrocks (2005), cuyo resultado se organizó mediante el siguiente protocolo: a partir de una muestra de $5 \mathrm{~g}$ se agregaron $6 \mathrm{ml}$ de hexametafosfato de sodio con $50 \mathrm{ml}$ de agua destilada y se centrifugó desechando el sobrenadante. En el mismo tubo se agregó solución de politungstato de sodio con densidad ajustada a $1,7 \mathrm{~g} / \mathrm{cc}$ y se centrifugó nuevamente. Luego se trasvasó el sobrenadante a otro tubo de centrífuga, en donde se diluyó la solución mediante el agregado de agua destilada y se centrifugó para sedimentar los granos de almidón y extraer el sobrenadante. Los preparados microscópicos se realizaron montando el material en glicerina con pipeta Pasteur sobre el portaobjeto y sellando el cubreobjeto con parafina. Para las descripciones de los granos de almidón así obtenidos se siguieron las pautas y descriptores cuali-cuantitativos propuestos por Babot (2007, 2009, 2011); Korstanje y Babot (2007); Babot et al. (2008); Holst et al. $2007 \mathrm{y} \mathrm{el}$ ICSN 2011 (The International Code for Starch Nomenclature). Las observaciones microscópicas fueron realizadas en un microscopio Leica DM 5000 con luz normal y polarizada.

Para el análisis del material biosilíceo se montó una alícuota de la misma muestra sin procesamiento en portaobjeto en medio líquido para observación tridimensional de los cuerpos. En el caso del procesamiento para microfósiles silíceos se puede consultar el protocolo seguido para este tipo de material en la bibliografía publicada (Bonomo et al. 2009; Zucol et al. 2010). Las observaciones y los recuentos se realizaron mediante un microscopio óptico Nikon Eclipse E 200, mientras que las microfotografías fueron tomadas con una cámara Nikon Coolpix S4 acoplada a este microscopio. Se realizó la cuantificación y determinación de fitolitos mediante morfotipos definidos sobre la base las clasificaciones morfológicas previas, siguiendo los descriptores de ICPNWG (2005) y las pautas clasificatorias de Twiss, et al. (1969); Bertoldi de Pomar (1971); Twiss (1992); Kondo et al. (1994) y Zucol (1996); autores que además se usaron para establecer las afinidades botánicas de los morfotipos diagnósticos.

\section{Características de la "Cuchara" de Tapera Vázquez}

La cuchara de cerámica (Fig. 2) ha sido recuperada en el Cerro Tapera Vázquez que está ubicado en la llanura de meandros adyacente al arroyo El Ceibo, dentro del Parque Nacional PreDelta, próximo a la ciudad de Diamante, Entre Ríos. Los estudios previos realizados en el sitio (Bonomo et al. 2011a) indican que Cerro Tapera Vázquez es un montículo bajo sobre un albardón preexistente, cuya elevación es producto del crecimiento acrecional generado por el descarte de materiales durante el asentamiento humano. El conjunto cerámico del sitio muestra la utilización de cuencos de formas abiertas y cerradas con superficies alisadas y la manufactura in situ de vasijas cocidas a cielo abierto. La presencia de apéndices zoomorfos y decoraciones con surco rítmico, junto con su edad de ca. 600 BP, su ubicación geográfica y ambiental, entran dentro del rango de lo que Ceruti (1993) ha caracterizado como entidad Goya-Malabrigo. Esta entidad arqueológica ha sido definida en base a una serie de rasgos estilísticos de la alfarería, principalmente los apéndices zoomorfos modelados, un patrón adaptativo orientado a la explotación de ambientes fluviales, el cultivo en huertos domésticos, las construcciones monticulares de tierra, un asentamiento de tipo aldeano y el desarrollo de jerarquías sociales (Ceruti 2003; Politis y Bonomo 2012).

En Cerro Tapera Vázquez se explotaron recursos acuáticos, sobre todo mamíferos (p. ej. Myocastor coypus, Hydrochaeris hydrochaeris, Cavia aperea, Blastocerus dichotomus y Ozotoceros bezoarticus), junto con peces y aves. El predomino del coipo con numerosas evidencias de modificación antrópica (huellas de corte, negativos de impacto y termoalteraciones) muestra que la ocupación estuvo principalmente orientada a la captura, procesamiento y consumo intensivo de esta especie. Los estudios de almidones y fitolitos permitieron identificar el uso y procesa- 
Análisis de residuos orgánicos y microfósiles silíceos de la "cuchara" de cerámica del sitio arqueológico Cerro Tapera Vázquez (Parque Nacional Pre-Delta, Argentina)

R. Museu Arq. Etn., São Paulo, n. 22: 31-50, 2012.

miento de plantas domésticas de maíz y porotos. En suma, los ocupantes del sitio serían grupos canoeros ribereños, con una compleja tecnología cerámica, cuya subsistencia se basaba en la caza de coipo, carpincho y cérvidos, en la pesca y el cultivo de vegetales domésticos.

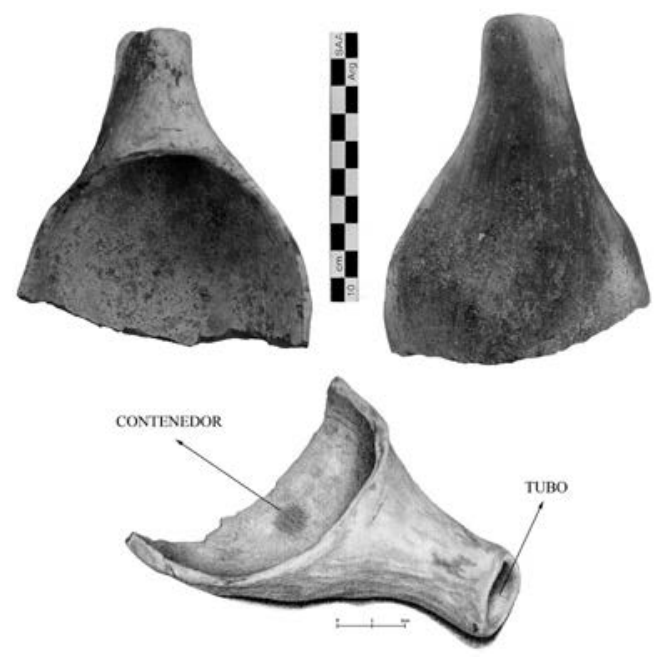

Figura 2: Cuchara de cerámica (n CTV.1.12.6) recuperada en el Cerro Tapera Vázquez. Arriba: fotografías con la vista superior e inferior. Abajo: dibujo señalando la parte interna del contenedor y el tubo.

La cuchara de cerámica de Cerro Tapera Vázquez fue recuperada en la base de un fogón con una concentración de carbones, tiestos cerámicos y restos óseos $\left(98\right.$ por $\left.\mathrm{m}^{2}\right)$. El interior del contenedor de la cuchara poseía sedimentos mezclados con espículas grandes de carbones que fueron identificadas en Bonomo et al. (2011a) como afines a Inga uruguensis (Fabaceae, Mimosoideae). Sin embargo, entre los carbones del fogón también se determinó la presencia de esta especie, cuya madera al quemarse se caracteriza por producir abundante humo. Esto parece indicar que los carbones incluidos en los sedimentos adheridos a la cuchara serían restos de la leña utilizada en el fogón.

La cuchara posee una fractura transversal que expone el delgado espesor de sus paredes e impide conocer su largo total y su morfología completa. Así alcanza los $11,4 \mathrm{~cm}$ de largo parcial, los $9,5 \mathrm{~cm}$ de ancho máximo y $0,5 \mathrm{~cm}$ de espesor máximo. El sector que corresponde al contenedor tiene forma elíptica, base redondeada y una profundidad máxima de $3,3 \mathrm{~cm}$. El labio tiene forma plana e irregular. El sector del tubo (o asa tubular según Serrano 1934) posee $5 \mathrm{~cm}$ de largo, un diámetro externo de $2,8 \mathrm{~cm}$ y uno interno de 1,7 que corresponde al orificio.

La superficie externa muestra marcas de emparejamiento e irregularidades que indican un alisado incipiente mientras que la superficie interna está alisada. La cocción es incompleta (con núcleo gris oscuro y márgenes rojizos). En la mayor parte de la superficie externa del contenedor y el tubo se observa una mancha ennegrecida producto de la carbonización del combustible usado cuando la pieza se expuso al fuego. Esta alteración en la base y bordes de la superficie externa podría representar una zona de mayor absorción de restos carbonosos durante el proceso de cocción o podría estar relacionada con su utilización para calentar sobre una llama alguna sustancia líquida o sólida. La superficie interna no muestra indicios de combustión.

El análisis de la pasta en corte fresco con lupa binocular permitió observar el predominio de inclusiones no plásticas de granulometría fina $(0,06-0,25 \mathrm{~mm})$, abundancia media (entre el 10 y $20 \%$ ) y formas subangulosas a subredondeadas. Las cavidades son escasas (inferiores a $10 \%)$ y la textura compacta.

\section{Resultados}

\section{Análisis de residuos orgánicos}

En la tabla 1 (Tab. 1) se detallan los resultados obtenidos a partir de las dos muestras obtenidas de la cuchara de cerámica, en forma conjunta con la muestra de sedimentos de la capa IV.

Los ácidos grasos identificados en la matriz sedimentaria (mirístico, palmítico, esteárico, oleico y su isómero, octadecenoico) se encuentran ampliamente distribuidos en el medio ambiente, no pudiendo identificarse a partir de los mismos un origen inequívoco. Por ello, su registro en el sedimento de la capa IV no representa un impedimento para evaluar el resto del perfil lipídico obtenido a partir del muestreo de la cuchara (Fig. 


\begin{tabular}{|c|c|c|c|}
\hline Compuesto & $\begin{array}{l}\text { Sedimen- } \\
\text { to (capa } \\
\text { IV) }\end{array}$ & $\begin{array}{c}\text { Contenedor de la } \\
\text { cuchara sumergido } \\
(10-090602)\end{array}$ & $\begin{array}{c}\text { Contenedor de la } \\
\text { cuchara por raspado } \\
(10-090603)\end{array}$ \\
\hline C12:0 - Ácido láurico & & 2,07 & \\
\hline C14:0 - Ácido mirístico & 2,87 & 2,36 & 1,39 \\
\hline C15:0 - Ácido pentadecanoico & - & 3,91 & 1,68 \\
\hline C16:0 - Ácido palmítico & 13,81 & 13,46 & 19,02 \\
\hline C16:1 - Ácido palmitoleico & - & 3,17 & \\
\hline C17:0 - Ácido heptadecanoico & - & 6,61 & 1,58 \\
\hline C17:1 - Ácido heptadecenoico & - & 1,10 & - \\
\hline C18:0 - Ácido esteárico & 17,83 & 7,52 & 11,16 \\
\hline C18:1 - Ácido oleico & 28,62 & 7,20 & 4,30 \\
\hline C18:1-Ácido octadecenoico (isómeros) & 36,87 & & \\
\hline C19:0 - Ácido nonadecanoico & 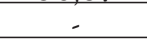 & 1,38 & 1,74 \\
\hline C19:1 - Ácido nonadecenoico & - & 1,07 & \\
\hline C20:0 - Ácido araquídico & - & 1,84 & 4.08 \\
\hline C20:1 - Ácido eicosenoico & - & 4,65 & \\
\hline C21:0 - Ácido henicosanoico & - & 1,17 & 2,35 \\
\hline C21:1-Ácido heneicosenoico & - & 1,09 & 5,69 \\
\hline C22:0 - Ácido behénico & - & 1,63 & 3,22 \\
\hline C22:1-Ácido erúcico & - & 2,94 & 5,77 \\
\hline C23:0 - Ácido tricosanoico & - & 1,28 & 2,17 \\
\hline C24:0 - Ácido lignocérico & - & 2,44 & 3,54 \\
\hline C25:0 - Ácido pentacosanoico & - & 1,97 & 1,32 \\
\hline C26:0 - Ácido hexacosanoico & - & 1,37 & 2,07 \\
\hline No determinados & - & 29,77 & 28,92 \\
\hline
\end{tabular}

Tabla 1: Resultados del análisis de residuos orgánicos (expresados en porcentajes). Los valores porcentuales no hacen referencia a la cantidad absoluta de cada ácido graso, sino a su presencia relativa en relación con el total de la muestra.

3 y 4) y realizar interpretaciones sobre la naturaleza de las sustancias analizadas y sobre sus posibles usos en el pasado. De hecho, es la presencia de otros compuestos más particulares detectados en las muestras la que puede ser utilizada como un medio para identificar el origen de las sustancias, al menos a grandes rasgos, diferenciando entre un posible origen animal o vegetal.

Los ácidos grasos más comúnmente distribuidos en la naturaleza son aquellos con número par de átomos de carbono en su composición, como por ejemplo el ácido esteárico (C18:0). Sin embargo, no es extraño detectar en los análisis cromatográficos ácidos grasos con número impar de carbonos, principalmente los ácidos pentadecanoico (C15:0) y heptadecanoico (C17:0). Estos dos ácidos grasos son sintetizados por bacterias y suelen detectarse en los tejidos grasos de mamíferos rumiantes a causa de las particularidades de su alimentación (Robinson et al. 1991; Craig et al. 2005). Asimismo, su presencia en muestras arqueológicas puede ser producto de la descomposición del residuo de uso post-descarte (Buonasera 2007). A ellos se suma en este caso, la presencia del ácido nonadecanoico (C19:0), ya detectado en muestras arqueológicas de la región pampeana bonaerense (González de Bonaveri y Frère 2002; Mazzia 2012) y del noroeste argentino (Babot 2004), e interpretado también como producto de la acción bacteriana sobre las sustancias.

Los ácidos grasos saturados de cadena larga o muy larga (con 20 o más átomos de carbono en su composición) pueden estar en muy pequeñas proporciones, por ejemplo por debajo del $1 \%$, tanto en animales como en vegetales. No obstante, en porcentajes relativos mayores, como en este caso que están presentes hasta con un 4,08\% (ácido araquídico), resultan característicos de las ceras vegetales que se encuentran en la superficie de las hojas o cáscaras de frutos (Robinson et al. 1991; Buenasera 2007). Particularmente, los ácidos grasos 20:0, 22:0, 24:0 y 26:0 registrados en la cuchara han sido hallados tanto en las mencionadas ceras vegetales como en aceites de frutos y semillas (Fankhauser 
Análisis de residuos orgánicos y microfósiles silíceos de la "cuchara" de cerámica del sitio arqueológico Cerro Tapera Vázquez (Parque Nacional Pre-Delta, Argentina)

R. Museu Arq. Etn., São Paulo, n. 22: 31-50, 2012.

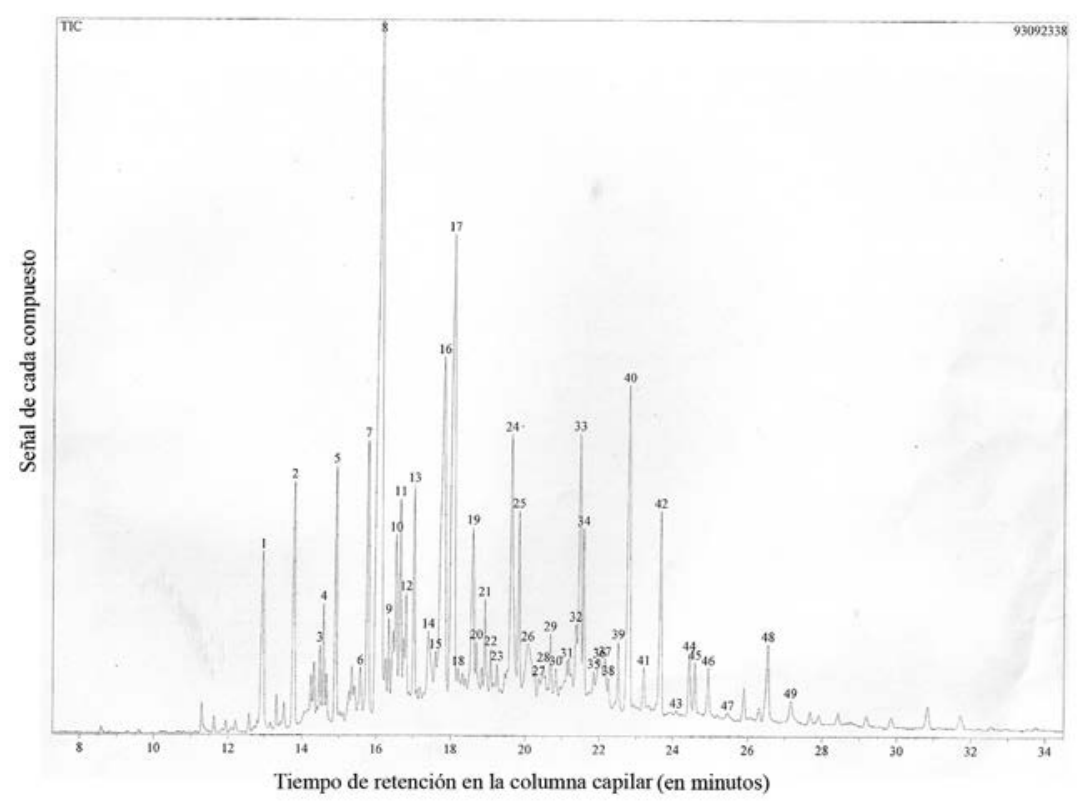

Figura 3: Cromatograma de la muestra 10-090602 tomada de la porción ancha de la cuchara por inmersión en solvente. Los diferentes picos del gráfico corresponden a los componentes de la mezcla que fue inyectada y separada mediante el análisis cromatográfico.

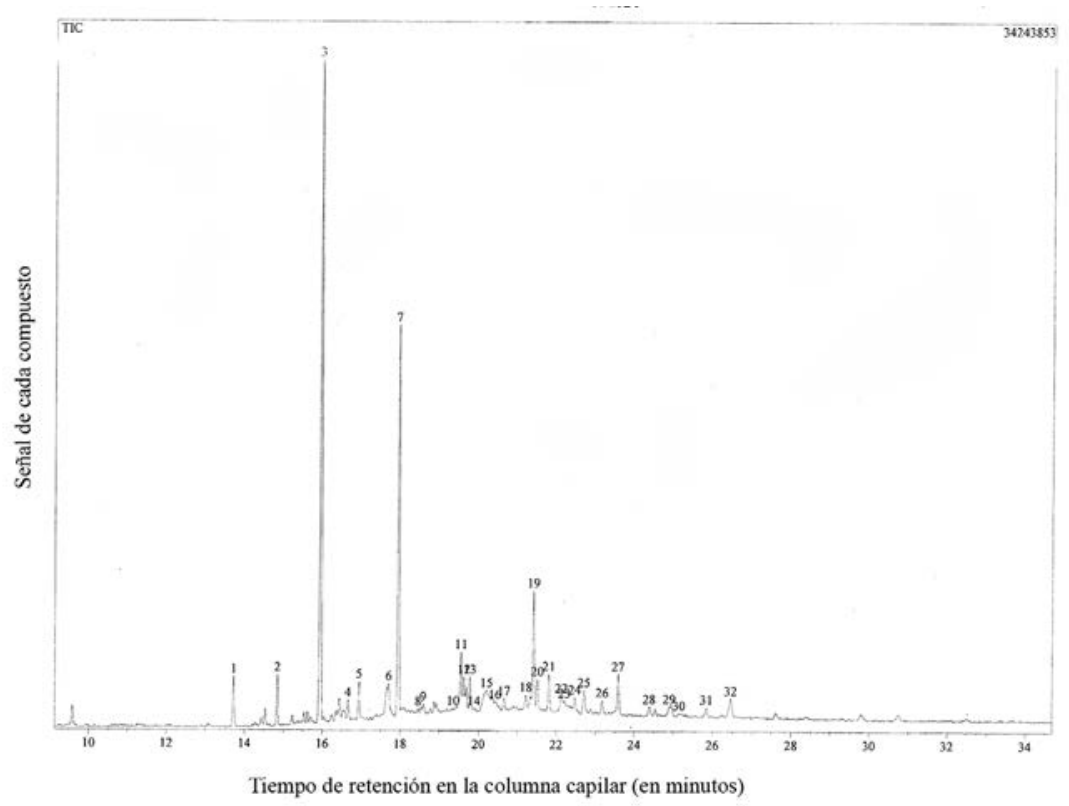

Figura 4: Cromatograma de la muestra 10-090603 tomada de la porción ancha de la cuchara por raspado de su superficie. 
1994). También se asocia con aceites de diversos frutos y semillas el ácido tricosanoico (C23:0), observado en numerosas muestras arqueológicas extraídas de instrumental lítico de molienda de California (Buonasera 2007).

La combinación de los ácidos grasos 19:0, 20:0, 21:0, 22:0 y 24:0 también ha sido interpretada como proveniente de ceras vegetales identificadas en instrumental lítico de molienda del noroeste argentino (Babot 2004). Esto se debe a que las ceras vegetales detectadas a partir de compuestos de cadena larga (con más de 20 átomos de carbono en su composición), en su mayoría saturados, y en combinaciones variables, son consideradas remanentes del procesamiento de plantas (Cañabate Guerrero y Sánchez Vizcaíno 1995). Existe una alta probabilidad de que las mismas sean aportadas por los recubrimientos protectores de frutas, hojas o semillas.

El ácido laúrico (C12:0) no presenta una distribución demasiado amplia en la naturaleza, cuando se encuentra en grasas animales sólo representa proporciones menores al $1 \%$, en tanto que en aceites vegetales puede superar notoriamente esos valores (Robinson et al. 1991; U.S. Testing Company, INC.). Este sería otro dato que apunta al origen vegetal de las sustancias. A esto puede sumarse el registro de los ácidos heptadecenoico $(\mathrm{C} 17: 1)$ y heneicosenoico (C21:1). Si bien no se han encontrado referencias bibliográficas de recursos actuales para estos ácidos grasos, los mismos fueron detectados en muestras experimentales a partir de objetos líticos con los que se procesaron vegetales (Mazzia más aún considerando los indicadores mencionados anteriormente que apuntan a un origen vegetal de las sustancias. Esta ausencia puede deberse a que se haya degradado a lo largo del tiempo, ya que, al tratarse de un ácido graso poli insaturado resulta más inestable frente a procesos de oxidación.

\section{Análisis de microfósiles}

En líneas generales, las tres muestras analizadas presentaron microfósiles tanto silíceos como almidonosos. Además, se hallaron diatomeas, espículas de espongiarios y un estomatociste de crysostomatácea (Fig. 5). En cuanto a la preservación, es visible el deterioro de los cuerpos principalmente en la superficie externa de los fitolitos. Mientras que en los granos de

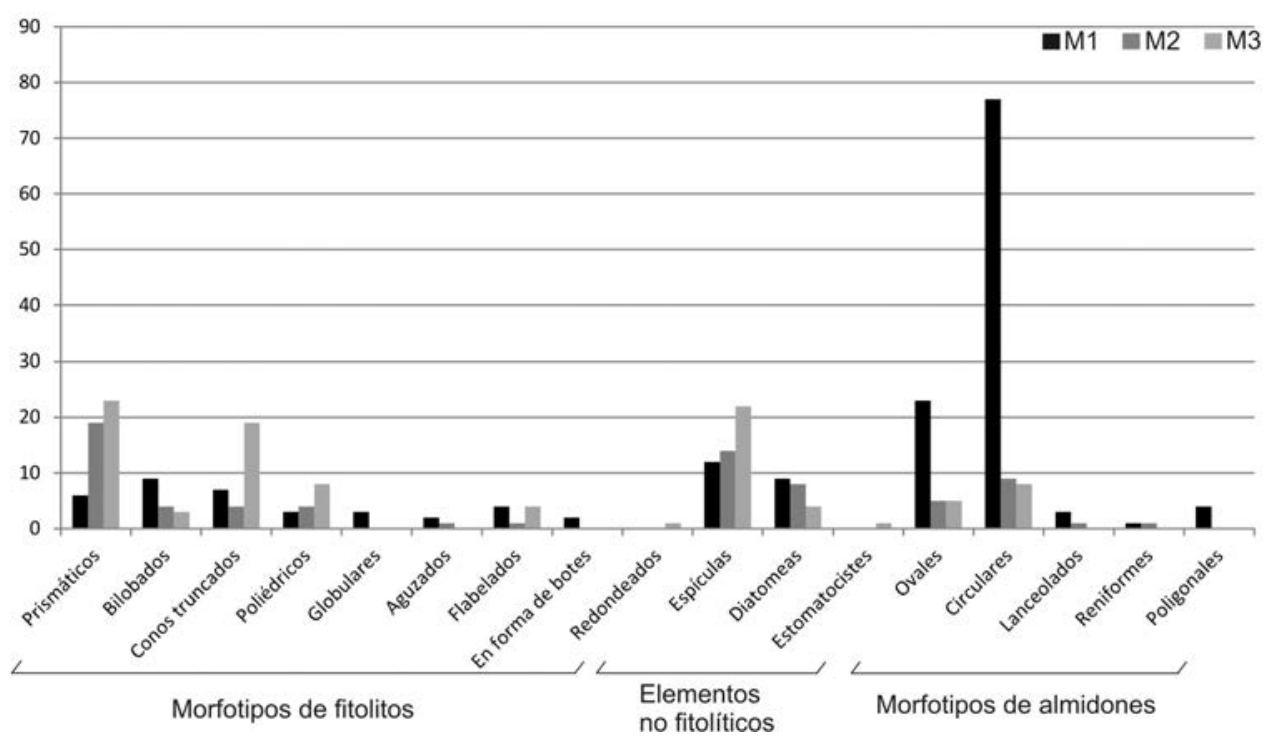

Figura 5: Abundancias de los diferentes microfósiles analizados en cada una de las muestras (M1, M2, M3). Valores del eje Y en recuentos por cada tipo de microfósil. 
Análisis de residuos orgánicos y microfósiles silíceos de la "cuchara" de cerámica del sitio arqueológico Cerro Tapera Vázquez (Parque Nacional Pre-Delta, Argentina)

R. Museu Arq. Etn., São Paulo, n. 22: 31-50, 2012.

almidón se observaron modificaciones como fragmentación de los granos (Fig. 6G-H) y daños en la cruz de extinción (Fig. 6P-Q, deterioros producidos por diferentes agentes corrosivos sensu Babot 2006; 2009).

A continuación se describen los resultados obtenidos en cada muestra. M1: en la superficie basal interna del contenedor predominan las formas fitolíticas bilobadas (Fig. 6a-c), en conos truncados (Fig. 6g) y las prismáticas (Fig. 6k). Se registraron además elementos flabelados, poliédricos, globulares (Fig. 6h), globulares facetados (Fig. 6f), aguzados (Fig. 6i) y en forma de bote. Entre los elementos no fitolíticos se hallaron espículas de espongiarios y diatomeas (Fig. 61). Esta superficie es la que presenta mayor abundancia y variabilidad de granos de almidón. Principalmente elementos de formas circulares (Fig. 6M-O) y en segundo término ovales, pero además se encuentran en menor abundancia, los lanceolados (Fig. 6I-J), los reniformes (Fig. 6C-D) y los poligonales (Fig. 6A-B, característicos sólo de esta muestra).

M2: la superficie interna del tubo presenta elementos prismáticos, los más abundantes en cuanto al registro fitolítico, y son menos frecuentes los poliédricos (Fig. 6e), los conos truncados y los bilobados (Fig. 6d). El tubo interno posee características similares a la base interna del contenedor en cuanto a la cantidad de espículas de espongiarios y de diatomeas (Fig. $6 \mathrm{~m})$, con abundancias comparables. Particularmente en esta muestra se observaron restos de material carbonoso. En lo que respecta a los granos de almidón, predominan los circulares y los ovales (Fig. 6E- F); también se observan lanceolados y reniformes.

M3: en la superficie externa se destacan los elementos prismáticos (Fig. 6ñ), los conos truncados, los poliédricos y escasos bilobados en relación con las muestras anteriores. Se observa una tendencia al aumento en esta muestra de las espículas de espongiarios (Fig. 6n) y la presencia en particular de un estomatociste de crysostomatácea (Fig. 6j). Los granos de almidón son principalmente circulares, y con menor abundancia ovales (Fig. 6K-L), siendo éstos los dos únicos tipos presentes en esta muestra.
En cuanto las afinidades botánicas, la muestra M1 es la que presenta menor abundancia de fitolitos, predominando los elementos de afinidad panicoide (bilobados). A diferencia de las muestras M2 y M3, están representados los elementos arecoides (globulares) y festucoides (en forma de botes). Se observan también espículas y diatomeas. En el contenido fitolítico de M1, además de formas panicoides, son destacables los elementos arecoides, ya que las palmeras son un recurso que pudo hallarse disponible en el entorno y no aparece en las otras superficies de la cuchara.

Las muestras M2 y M3 presentan mayor abundancia de microfósiles silíceos que la superficie interna. Predominan los elementos graminoides (como los prismáticos, los poliédricos y los flabelados) y danthonioides (formas en cono truncado). Los morfotipos pooides (redondeados) son característicos de la muestra M3. Mientras que los bilobados, los aguzados y los fitolitos en forma de bote, son menos abundantes o están ausentes en las muestras M2 y M3. En el caso de la superficie externa predominaron las espículas frente a las diatomeas y se identificó un estomatociste de crysostomatacea.

En lo que respecta al contenido almidonoso, la superficie interna, M1, es la que posee la mayor cantidad de granos de almidón, algunos de los cuales pudieron asociarse con formas diagnósticas. Las formas de contorno poligonal, que en algunas muestras presentaron fisuras visibles, se ajustan a las descriptas para variedades de Zea mays (Korstanje y Babot 2007; Babot et al. 2008; Babot 2011; Bonomo et al. 2011b) ya que además coinciden en sus dimensiones (aproximadamente 20 micrones).

La representación de los elementos fitolíticos panicoides (incluyendo los tipos en forma de cruz) y los granos de almidón característicos de maideas en M1 permite estimar que el maíz (Zea mays) pudo ser parte de los materiales que tuvieron contacto con la cuchara. En tanto que los granos reniformes observados son similares a los citados para Phaselous vulgaris (poroto) por Korstanje y Babot (2007), Babot et al. (2007) y Bonomo et al. (2011b). Los almidones con formas lanceoladas observados en la superficie interna y el tubo, han 

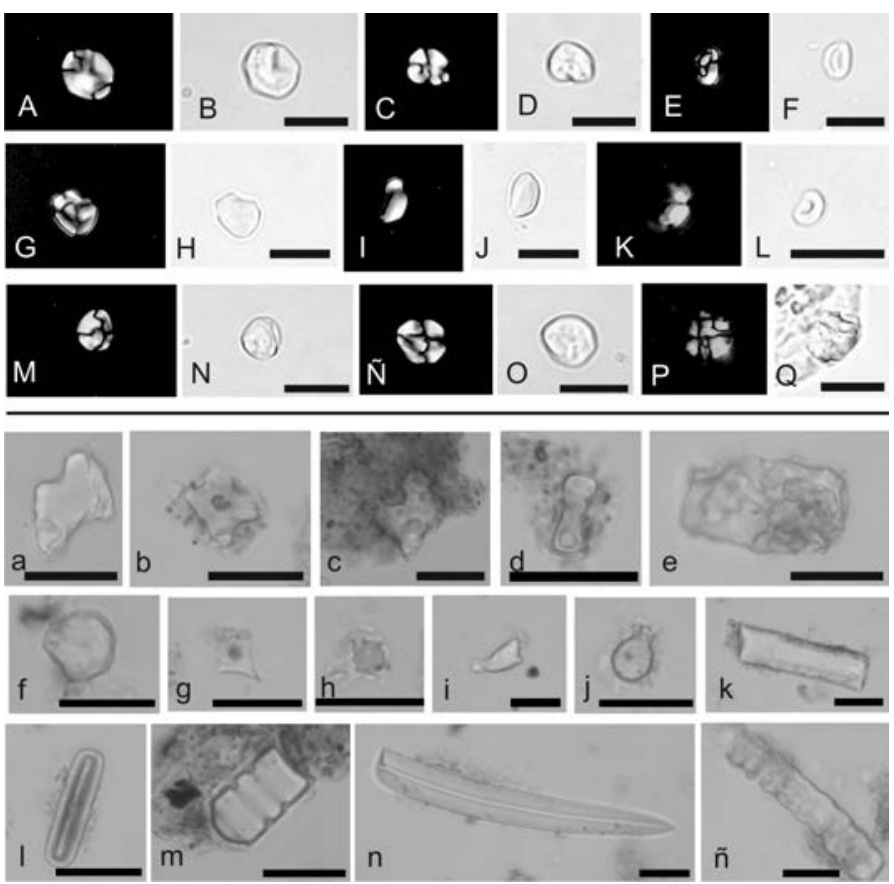

Figura 6: A-Q: Granos de almidón. A-B Poligonal, C-D Reniforme, E-F Oval, G-H Grano fragmentado, I-J Lanceolado, K-L Oval, M-O Circulares y P-Q Oval (escala 50 micrones). a-k y ñ: Fitolitos. a-d Bilocados, f Globular facetado, $g$ en forma de cono truncado, h Globular, i Aguzado, j Estomatociste de crysostomatácea, $\mathrm{k}$ Fitolito prismático, 1-m Diatomeas y n Espícula de espongiario (escala 20 micrones).

sido mencionadas por Korstanje y Babot (2007) para Canna edulis (achira), junto a los fitolitos de borde facetados que producen sus tubérculos, hallados también en este caso. Las cannáceas han sido citadas también en otro de los sitios de las islas del Paraná, con similar cronología y contexto arqueológico (Castiñeira et al. 2013).

\section{Discusión}

Con fines comparativos y para evaluar si existe algún patrón en los tamaños, se registraron las dimensiones de otras cucharas de cerámica recuperadas en las islas del Delta Superior ${ }^{3}$ y la lla-

(3) En este sector bajo estudio además se han registrado cucharas de cerámica en el Cerro El Lucerito y el Cerro Grande de la isla de los Marinos. nura aluvial del Paraná (Tab. 2; Fig. 7). Las nueve cucharas muestran una importante variabilidad en sus medidas generales, lo cual no apunta a una estandarización de los tamaños de estas piezas que comparten una forma común. Los largos varían entre 17,5 y $7,7 \mathrm{~cm}$, los anchos entre 9,5 y 4,4 cm (siendo la de CTV la más ancha) y los espesores entre 0,8 y $0,4 \mathrm{~cm}$. La parte del contenedor tiene forma circular a oval y, a excepción del ejemplar del Arroyo Leyes, una muy baja capacidad de contención. El largo del contenedor es menor que el general de la pieza por la presencia de los tubos que tienen desde 5,8 hasta 1,8 cm de largo, mientras que el ancho del contenedor coincide con el general. Los diámetros interno $(1,9-1 \mathrm{~cm}) \mathrm{y}$ externo $(3,5-1,6 \mathrm{~cm})$ de los tubos son las medidas que más se mantienen en las distintas piezas, mostrando una búsqueda de regularidad en los orificios de esta parte de la pieza vinculada seguramente con una función específica. Las paredes 
Análisis de residuos orgánicos y microfósiles silíceos de la "cuchara" de cerámica del sitio arqueológico Cerro Tapera Vázquez (Parque Nacional Pre-Delta, Argentina)

R. Museu Arq. Etn., São Paulo, n. 22: 31-50, 2012.

internas y externas de las cucharas están alisadas. En dos casos se observó ennegrecimiento de las superficies externas, mientras que las superficies internas de ningún ejemplar muestran evidencias de combustión; esto es un dato en contra de su uso como lámparas (Copley et al. 2005; Menacho 2007). La única pieza que está decorada es la recuperada en el Arroyo Leyes que posee el borde del contenedor con incisiones punteadas.

Pequeños recipientes con un tubo lateral, semejantes aunque no iguales, han sido dados a conocer en la alfarería de la isla de Marajó en la desembocadura del Amazonas (Palmatary 1949: lámina 42d-e; Meggers y Evans 1957: lámina 81; Roosvelt 1991: Fig. 1.23B; Hilbert 1992: Fig. 5-13) y en Costa Rica (Wassén 1965: figura 2). En Marajó, la parte del contenedor tiene forma circular a oval, entre 2 a $4 \mathrm{~cm}$ de profundidad (Meggers y Evans 1957). Como se observa en las diez piezas incluidas en la Tabla 2 (Fig. 8), sus dimensiones principales entran dentro del rango de medidas registradas para las cucharas del Paraná. Sin embargo, sus tubos suelen inclinarse hacia arriba, tienen diámetros menores y son frecuentemente más cortos, por lo que parecen menos asociados a una función simultánea de asas. Otras diferencias significativas observadas con relación a las piezas del Paraná, es que los recipientes analizados de Marajó generalmente se cierran en el borde (algo que podría vincularse con el contenido de líquidos) y poseen mayor grado de elaboración. Sus superficies internas y externas pueden tener pintura o engobe de color rojo, naranja y/o blanco. Las superficies externas, incluyendo contenedor, tubo y borde, pueden estar decoradas con incisiones-excisiones, así como presentar apliques y modelados zoomorfos en el extremo opuesto al tubo (véase también Palmatary 1949; Hilbert 1992).

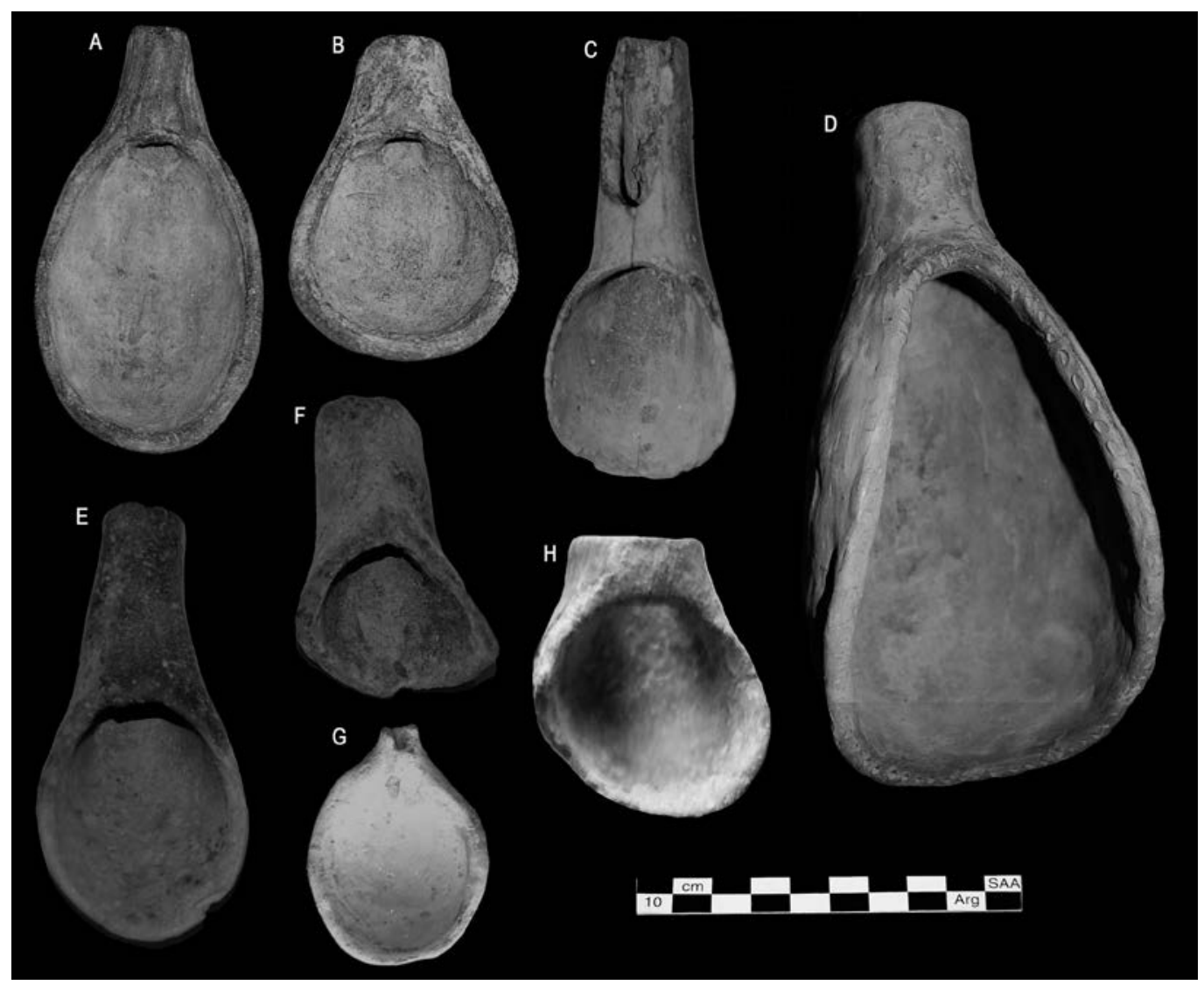

Figura 7: Cucharas recuperadas en el Delta Superior y la llanura aluvial del Paraná. Referencias: A-B Isla del Pillo; C Los Laureles; D A Leyes; E-F San Fabián; G Co. Pancho Lares y H Co. Barrancas 


\begin{tabular}{|c|c|c|c|c|c|c|c|c|c|}
\hline \multirow{2}{*}{ Procedencia } & \multirow{2}{*}{$\begin{array}{l}\text { Repositorio } \\
\text { (No catálogo) }\end{array}$} & \multicolumn{3}{|c|}{$\begin{array}{c}\text { Dimensiones } \\
\text { generales }\end{array}$} & \multicolumn{2}{|c|}{$\begin{array}{c}\text { Contene- } \\
\text { dor }\end{array}$} & \multicolumn{3}{|c|}{ Tubo } \\
\hline & & $\mathrm{L}^{\circ}$ & A & $\mathrm{E}$ & $\mathrm{L}$ & $\mathrm{A}$ & $\mathrm{L}$ & $\begin{array}{c}\text { Diámetro } \\
\text { interno }\end{array}$ & $\begin{array}{c}\begin{array}{c}\text { Diámetro } \\
\text { externo }\end{array} \\
\end{array}$ \\
\hline $\begin{array}{l}\text { Co. Tapera } \\
\text { Vázquez }\end{array}$ & $\begin{array}{l}\text { MLP** } \\
\text { (CTV-1.12.6) }\end{array}$ & $11,4^{*}$ & 9,5 & 0,5 & - & 9,5 & 5 & 1,7 & 2,8 \\
\hline Co. Barrancas & Col. O. Rodríguez & 7,7 & 6,3 & 0,5 & 5,8 & 6 & 1,8 & 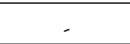 & 3,3 \\
\hline $\begin{array}{l}\text { Co. Pancho } \\
\text { Lares }\end{array}$ & $\begin{array}{l}\text { Col. C. Flores y M. } \\
\text { Nuñez }\end{array}$ & $6,1^{*}$ & 4,4 & 0,4 & 4,9 & 4 & 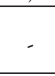 & - & 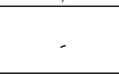 \\
\hline Los Laureles & Col. E. Pressel & 10,6 & 8,8 & 0,4 & 5,2 & 8,8 & 5,4 & 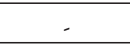 & 1,6 \\
\hline $\begin{array}{l}\text { Isla del Pillo } \\
\text { (Entre Ríos) }\end{array}$ & $\mathrm{MCV}$ & 11,3 & 5,8 & 0,5 & 7,4 & 5,1 & 3,4 & 1 & 1,6 \\
\hline $\begin{array}{l}\text { Isla del Pillo } \\
\text { (Entre Ríos) }\end{array}$ & $\mathrm{MCV}$ & 8,8 & 6 & 0,7 & 5,2 & 4,8 & 2,9 & 1,5 & 2,3 \\
\hline $\begin{array}{l}\text { San Fabián } \\
\text { (Santa Fe) }\end{array}$ & MHPR & 11,2 & 4,9 & 0,4 & 5,4 & 4,9 & 5,8 & 1,2 & 2,1 \\
\hline $\begin{array}{l}\text { San Fabián } \\
\text { (Santa Fe) }\end{array}$ & MHPR & $7,4^{*}$ & 4,7 & 0,7 & $\mathrm{~F}$ & 4,7 & 4,3 & 1,1 & 2,7 \\
\hline $\begin{array}{l}\mathrm{A}^{\circ} \text { Leyes (Santa } \\
\mathrm{Fe} \text { ) }\end{array}$ & MLP-D25-CJF & 17,5 & 7,8 & 0,8 & 13 & 7,8 & 4,5 & 1,9 & 3,5 \\
\hline Isla de Marajó & UPM- (SA1726) & 13,5 & 6 & 0,4 & 5 & 4,5 & 2,7 & 0,7 & 1,2 \\
\hline $\begin{array}{l}\text { Camutins (isla } \\
\text { de Marajó) }\end{array}$ & $\begin{array}{l}\text { UPM-Col. W.C. } \\
\text { Farabee (SA1724) }\end{array}$ & 12,5 & 6 & 0,8 & 7,5 & 4,7 & 3 & 0,5 & 0,8 \\
\hline $\begin{array}{l}\text { Camutins (isla } \\
\text { de Marajó) }\end{array}$ & $\begin{array}{l}\text { UPM-Col. W.C. } \\
\text { Farabee (SA1727) }\end{array}$ & 11,2 & 10 & 0,8 & 7,9 & 7,7 & 2 & 0,8 & 1,5 \\
\hline Isla de Marajó & $\begin{array}{l}\text { MAE-GR2/0266-Col. } \\
\text { Graciete }\end{array}$ & 8,2 & 5,8 & 0,9 & 4,7 & 4,1 & 1,8 & 0,6 & 1,1 \\
\hline Isla de Marajó & $\begin{array}{l}\text { MAE-GR2/0273-Col. } \\
\text { Graciete }\end{array}$ & 8,3 & 5,3 & 0,8 & 4,1 & 4,1 & 2,8 & 0,8 & 1,3 \\
\hline Isla de Marajó & $\begin{array}{l}\text { MAE-GR2/0275-Col. } \\
\text { Graciete }\end{array}$ & 8,9 & 4,7 & 0,7 & 3,4 & 3 & 2,1 & 0,6 & 1,4 \\
\hline Isla de Marajó & $\begin{array}{l}\text { MAE-GR2/0267-Col. } \\
\text { Graciete }\end{array}$ & 9,5 & 4,7 & 0,5 & 4,3 & 3,2 & 2,1 & 0,5 & 1,1 \\
\hline Isla de Marajó & $\begin{array}{l}\text { MAE-GR2/0274-Col. } \\
\text { Graciete }\end{array}$ & 9,7 & 6,1 & 0,6 & 5,8 & 4,8 & 2 & 0,4 & 1,2 \\
\hline Isla de Marajó & $\begin{array}{l}\text { MAE-GR2/0268-Col. } \\
\text { Graciete }\end{array}$ & 8,1 & 4,7 & 0,4 & 4 & 2,7 & 1,4 & 0,5 & 1,2 \\
\hline Isla de Marajó & $\begin{array}{l}\text { MAE-GR2/0272-Col. } \\
\text { Graciete }\end{array}$ & 10,5 & 6,1 & 0,5 & 5,3 & 3,9 & 2,2 & 0,7 & 1,4 \\
\hline
\end{tabular}

Tabla 2: Dimensiones en centímetros de las cucharas recuperadas en el Paraná comparadas con las de la isla de Marajó (Pará).

MLP=Museo de La Plata; MHPR= Museo Histórico Provincial "Dr. Julio Marc"; MCV= Museo de la Ciudad "Carlos Amador", Victoria; UPM=University of Pennsylvania Museum of Archaeology and Anthropology; MAE=Museu de Arqueologia e Etnologia. Notas: *pieza fracturada; ${ }^{* *}$ repositorio temporario.

Se ha especulado mucho con relación a los posibles usos de estos singulares recipientes recuperados en Brasil y Costa Rica. En la Fase Marajoara también se los ha clasificado como cucharas o cucharones a los que se les colocaba un palito como mango en el interior del corto tubo (Meggers y Evans 1957; véase también Palmatary 1949:315). Sobre la base de sus características formales, Megger y Evans (1957) descartan su función como pipa porque el hueco del tubo queda por encima del posible contenido a quemar. Por otro lado se los consideró lámparas o recipientes para beber líquidos ${ }^{4}$ (Farabee 1921). La mayoría

(4) Este mismo principio funcional fue atribuido a las pacchas de cerámica y madera con tubos laterales para beber líquidos que se registran en baja frecuencia en momentos pre y post-hispánicos en los Andes Centrales (Lothrop 1956). 
Análisis de residuos orgánicos y microfósiles silíceos de la "cuchara" de cerámica del sitio arqueológico Cerro Tapera Vázquez (Parque Nacional Pre-Delta, Argentina)

R. Museu Arq. Etn., São Paulo, n. 22: 31-50, 2012.

de los autores (Wassén 1965; Schultes 1976; Roosvelt 1991; Hilbert 1992; Schaan 1996) en base a su morfología, pequeño tamaño, decoración zoomorfa y a ciertos paralelismos etnográficos consideran que son inhaladores de sustancias alucinógenas utilizados durante rituales y ceremonias. Sin embargo, aún no se ha reportado evidencia arqueobotánica que corrobore esto.

En nuestro caso de estudio, el perfil lipídico registrado en la cuchara cerámica de Cerro Tapera Vázquez indica que en el pasado esta pieza pudo haber contenido recursos vegetales, pudiendo incluir aceites de semillas o ceras provenientes del recubrimiento de frutos, hojas o semillas. El análisis de microfósiles también apoya la utilización de vegetales. Según estos indicadores, pudo contener tanto partes de gramíneas o palmeras, como diferentes productos almidonosos provenientes de Zea mays, Phaselous vulgaris y probablemente de las Cannaceae (como se ha observado en otros sitios de la región, Bonomo et al. 2011a y b y Castiñeira et al. 2013).

Las especies de cannaceas poseen diversos usos medicinales, como Canna glauca L., cuyo rizoma se emplea como diurético o en baños para los dolores de pies (Lahitte et al. 1997), o Canna indica L., cuyos tallos, hojas y raíces tienen propiedades curativas para la tos, las infecciones de la piel y como diurético, respectivamente, por mencionar algunas (Mejia y Rengifo 2000). Además, se ha citado el uso de Canna edulis en distintas partes del NOA y Chile (p. ej. Muñoz Ovalle 2001). Por su parte, los porotos y el maíz están entre los principales cultivos americanos. En el caso del maíz, las primeras crónicas de las Tierras Bajas del Brasil muestran que era utilizado principalmente para la obtención de bebidas fermentadas y, en mucha menor medida, para su consumo cuando los granos estaban inmaduros (Barghini 2004).

Las diatomeas y espículas presentes tanto en la superficie interna del contenedor como en el tubo indican además un contenido ácueo o niveles constantes de humedad sobre estas superficies de la cuchara. En la superficie externa en cambio las diatomeas se reducen notablemente, dominan las espículas y hay un estomatociste. Esto apunta a una mayor sequedad de la superficie exterior del recipiente. Las condiciones de preservación de los microfósiles botánicos, con superficies corroídas y bordes fragmentados, el material carbonoso adherido

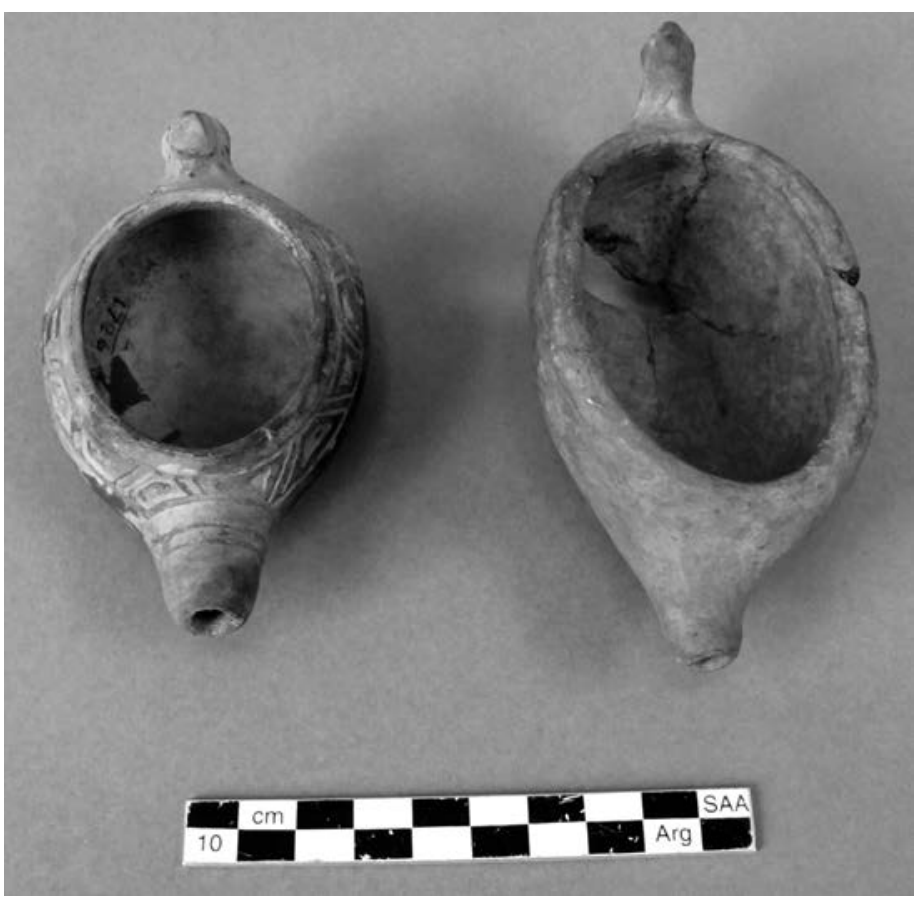

Figura 8: Pequeños recipientes con un tubo lateral recuperados en la isla de Marajó. 
en los cuerpos silíceos y la fragmentación en los granos de almidón (Babot, 2006), permiten suponer que hubo un calentamiento de los vegetales identificados. Posiblemente la mancha ennegrecida, observada en la superficie externa de la cuchara, y las delgadas paredes del recipiente, que favorecen la rápida transmisión del calor, estén vinculadas con ello.

\section{Conclusiones}

Los ácidos grasos que se han preservado durante seis siglos indican que la cuchara contuvo recursos vegetales. La gran cantidad y variabilidad de ácidos grasos y de microfósiles acumulados apuntan a una buena preservación de las sustancias lipídicas a lo largo del tiempo. Más que una función específica, la pieza parece haber tenido múltiples usos. La morfología de la pieza con un pequeño contenedor asociado a un tubo lateral, donde se registraron altos contenidos de organismos vinculados a condiciones ácueas, sumado al delgado espesor de sus paredes y a las alteraciones de la superficie externa por la exposición al fuego, permiten proponer que una de sus funciones fue para calentar y beber líquidos. Las pequeñas dimensiones de estas piezas apuntan a un uso individual, lo cual no implica que su contenido no pudiera ser compartido y circulado entre distintos individuos. El registro de microfósiles apoya la evidencia brindada por los ácidos grasos en cuanto a que el interior del recipiente contuvo variados recursos vegetales nutritivos en bajas cantidades. Entre ellos se destacan el maíz, los porotos y la achira, cuya presencia podría ser producto de distintos eventos de uso de la cuchara para la preparación, servicio y consumo de alimentos, sustancias medicinales y/o bebidas fermentadas.

Para finalizar, esta contribución se enmarca dentro de los estudios de silicofitolitos y almidones que se están desarrollando en el Delta del río Paraná (Bonomo et al. 2011a y b; Sánchez et al. 2011). Estas investigaciones buscan alternativas analíticas para contrarrestar la escasez de macrorrestos vegetales que se restringen a espículas de carbón y endocarpos de frutos de palmeras, sumados a algún artefacto en resina. A partir de estos estudios se han identificado vegetales silvestres (Prosopis sp., Palmáceas y elementos oryzoides) y se ha corroborado la hipótesis derivada de las fuentes escritas en cuanto a que las poblaciones guaraníes y no guaraníes de la región cultivaban plantas, tales como maíz (Zea mays), porotos (Phaseolus), zapallo (Cucurbitaceae) y posiblemente mandioca (Manihot). De esta manera estas investigaciones han permitido establecer con evidencia arqueobotánica que el Delta del Paraná fue uno de los límites meridionales de la agricultura precolombina en las Tierras Bajas sudamericanas.

\section{Agradecimientos}

A Gabriela Hassan por las sugerencias sobre las diatomeas, a Violeta Di Prado por su ayuda con la descripción de la cuchara y la bibliografía facilitada, a Klaus Hilbert por escanear y enviarnos su trabajo sobre Marajó, a Alejandro Zucol por la lectura y contribuciones al manuscrito y a Carolina Silva por el dibujo de la figura 2. A Clark Erickson, Marisa Afonso, Eduardo Góes Neves y Fabián Letieri por las facilidades brindadas para el estudio de las piezas depositadas en el Penn Museum de la University of Pennsylvania, el Museu de Arqueologia e Etnologia de la Universidade de São Paulo y el Museo Histórico Provincial "Dr. Julio Marc" de Rosario. Este trabajo fue financiado con los proyectos "Un abordaje arqueológico regional de las poblaciones prehispánicas del sudeste de la región pampeana y del Delta Superior del río Paraná" (PIP-CONICET 1283) y "Las estructuras monticulares del Delta Superior del Paraná” (PICT 0665). 
Análisis de residuos orgánicos y microfósiles silíceos de la "cuchara" de cerámica del sitio arqueológico Cerro Tapera Vázquez (Parque Nacional Pre-Delta, Argentina)

R. Museu Arq. Etn., São Paulo, n. 22: 31-50, 2012.

BONOMO, M.; COLOBIG, M.; MAZZIA, N. Analysis of organic residues and siliceous microfossils of the ceramic "spoon" from Cerro Tapera Vazquez archaeological site (Pre-Delta National Park, Argentina). R. Museu Arq. Etn., São Paulo, n. 22: 31-50, 2012.

\begin{abstract}
The aim of this study is to establish the function of a ceramic spoon from Cerro Tapera Vázquez archaeological site in the Pre-Delta Parana River (Argentina). For this purpose, the inner surface residues of this artifact were studied by fatty acids, siliceous microfossils and starches analysis. Additionally, morphological attributes as well as size and use-alterations were considered in order to compare with other ceramic spoon proposed collections surveyed in the region. Based on the obtained information regarding the small open shape of this ceramic container, the thin thickness of its walls, the identified residues, the humidity concentration recorded on the inside of the tube and the signs of thermal alteration in most of the external surface, it is proposed that the spoon was used to heat up and drink liquids made out of vegetables.
\end{abstract}

Keywords: Fatty acids, Phytolith, Starch, Paraná Delta, Late Holocene

\title{
Referências bibliográficas
}

BABOT, M. P.

2006 Damage on starch from processing Andean food plants. En: Torrence, R.; Barton, H. (Eds.) Ancient Starch Research. California, Left Coast Press:66-72.

BABOT, M. P.

2004 Tecnología y utilización de artefactos de molienda en el Noroeste Prehispánico. Tesis doctoral inédita, Facultad de Ciencias Naturales e IML, Universidad Nacional de Tucumán. Argentina.

BABOT, M. P.

2007 Granos de almidón en contextos arqueológicos: posibilidades y perspectivas a partir de casos del Noroeste Argentino. En: Marconetto, B.; Babot, P.; Oliszewski, N. (Eds.) Paleoetnobotánica del cono Sur: Estudios de caso y propuestas metodológicas: $95-125$.

BABOT, M. P.

2009 Procesamiento de tubérculos y raíces por grupos agropastoriles del noroeste argentino prehispánico. Análisis de indicadores en residuos de molienda. En: Capparelli, A.; Chevallier, A.; Pique, R. (Eds.) La alimentación en la América precolombina y colonial. Una aproximación interdisciplinaria. Treballs D' Etnoarqueologia 7:67-81.

BABOT, M. P.

2011 Cazadores-recolectores de los andes centro-sur y procesamiento vegetal. Una discusión desde la puna meridional argentina (ca. 7.000-3.200 años A.P.). En: Aldenderfer, M.; Flores Blanco, L. A. (Eds.). Chúngara 43(1):413-432.

BABOT, M. P.; OLISZEWSKI N.; GRAU, A.

2007 Análisis de caracteres macroscópicos y microscópicos de Phaseolus vulgaris (Fabaceae, Faboideae) silvestres y cultivados del Noroeste Argentino: Una aplicación en arqueobotánica. Darwiniana 45(2):149-162.

BABOT, M. P.; ESCOLA, P.S.; HOCSMAN, S.

2008 Microfósiles y atributos tecno- tipológicos: Correlacionando raederas de módulo grandísimo con sus desechos de talla de mantenimiento en el Noroeste Argentino. En: Korstanje M.A.; M. del P. Babot (Eds.): Matices Interdisciplinarios en Estudios Fitoliticos y de Otros Microfósiles. BAR International Series S1870: 187-200.

BARGHINI, A.

2004 milho na América do Sul Pré-Colombiana: uma história natural. Pesquisas, Antropologia 61:11-170. 
BERTOLDI DE POMAR, H.

1971 Ensayo de clasificación morfológica de los silicofitolitos. Ameghiniana 8(3-4): 317-328

BONDIA PONS, I.

2007 Estudio del perfil de ácidos grasos en la evaluación de la dieta mediterránea como patrón de dieta saludable en poblaciones europeas. Tesis doctoral inédita. Facultad de Farmacia, Universidad de Barcelona, España.

BONOMO, M.; ZUCOL, A.; GUTIÉRREZ TÉLLEZ, B.; CORADEGHINI, A.; VIGNA, M. S.

2009 Late Holocene Palaeoenvironments of the Nutria Mansa 1 Archaeological Site, Argentina. Journal of Paleolimnology 41(2):273-296.

BONOMO, M.; COLOBIG M. M.; PASSEGGI, E.; ZUCOL, A. F.; BREA, M.

2011 Multidisciplinary studies at Cerro Tapera Vázquez site, Pre-Delta National Park, Argentina: The archaeological, sedimentological and paleobotanical evidence. Quaternary International: 245:48-61.

BONOMO, M.; ACEITUNO BOCANEGRA, F. J.; POLITIS, G.; POCHETTINO, M. L.

2011b Pre- hispanic horticulture in the Paraná Delta (Argentina): Archaeological and historical evidence. World Archaeology 43(4):557-579.

BOUDREAUX, E. A., III.

2010 A functional analysis of Mississippian ceramic vessels from Town Creek. Southeastern Archaeology 29(1):8-30.

BUONASERA, T.

2007 Investigating the presence of ancient absorbed organic residues in groundstone using GCeMS and other analytical techniques: a residue study of several prehistoric milling tools from central California. Journal of Archaeological Science 34:1379-1390.

CAÑABATE GUERRERO, M. L.; SÁNCHEZ VIZCAÍNO, A.

1995 Análisis de indicadores bioquímicos del contenido de recipientes arqueológicos. Complutum 6:281-291.

CASTIÑEIRA, C.; BLASI A.; POLITIS G.; BONOMO, M.; DEL PUERTO L.; HUARTE R.; CARBONARI J.; MARI F.; GARCÍA-RODRÍGUEZ, F.

2013 The Origin and Construction of Pre-Hispanic Mounds in the Upper Delta of the Paraná River (Argentina). Archaeological and Anthropological Sciences 5(1): 37-57.

CERUTI, C. N.

1993 Arqueología. En: Renna, A. (Ed.) Nueva Enciclopedia de la Provincia de Santa Fe, IV. Santa Fe, Ediciones Sudamérica:557-580.
CERUTI, C. N.

2003 Entidades culturales presentes en la cuenca del Paraná Medio (margen entrerriana). Mundo de Antes 3:111-135.

COLOBIG, M. M.

2011 Estudios paleoetnobotánicos en sitios del borde oriental de Tandilia (Provincia de Buenos Aires). Pautas de aprovechamiento y uso de recursos vegetales en las sociedades de cazadoresrecolectores. Tesis doctoral Inédita. Facultad de Humanidades y Artes. Universidad Nacional de Rosario, Argentina.

COlOBIG, M. M.

2012 Estudios paleoetnobotánicos en muestras del sitio 1, Localidad arqueológica lobería I, Buenos Aires, Argentina: aproximación al manejo de recursos vegetales. Revista Relaciones de la Sociedad Argentina de Antropología. En prensa.

COPLEY, M. S.; BLAND, H. A.; ROSE, P., HORTON, M.; EVERSHED, R. P.

2005 Gas chromatographic, mass spectrometric and stable carbon isotopic investigations of organic residues of plant oils and animal fats employed as illuminants in archaeological lamps from Egypt. Analyst 130: 860-871.

CRAIG, O.E.; TAYLOR, G.; MULVILLE, J.; COLLINS, M. J.; PARKER PEARSON, M.

2005 The identification of prehistoric dairying activities in the Western Isles of Scotland: an integrated biomolecular approach. Journal of Archaeological Science 32:91-103.

DEBOER, W. R. Y LATHRAP, D. W.

1979 The Making and Breaking of Shipibo-Conibo Ceramics. En: Kramer, C. (Ed.) Ethnoarchaeology: Implications of Ethnography for Archaeology. New York, Columbia University Press:102-138.

EVERSHED, R. P.

1993 Biomolecular archaeology and lipids. World Archaeology 25(1):74-93.

EVERSHED, R. P.

2008 Organic Residue Analysis in Archaeology: The Archaeological Biomarker Revolution. Archaeometry 50(6):895-924.

EVERSHEAD, R. P.; HERON, C.; CHARTERS, S.; GOAD, L. J.

1992 Chemical analysis of organic residues in ancient pottery: methodological guidelines and applications. En: White, R.; H. Page (Eds.): Organic residues in archaeology: their identification and analysis. York, Uni- 
Análisis de residuos orgánicos y microfósiles silíceos de la "cuchara" de cerámica del sitio arqueológico Cerro Tapera Vázquez (Parque Nacional Pre-Delta, Argentina)

R. Museu Arq. Etn., São Paulo, n. 22: 31-50, 2012.

ted Kingdom Institute for Conservation, Archaeology Section:11-24.

FANKHAUSER, B.

1994 Protein and lipid analysis of food residues. En: Hather, J. G. (Ed.): Tropical Archaeobotany: Applications and New Developments. Londres, Routledge:227-250.

FARABEE, W.C.

1921 Explorations at the mouth of the Amazon. The Museum Journal, University of Pennsylvania 12:142-161.

FEISER, L. F.; FEISER, M.

1960 Química orgánica. México, Ed. Girjalbo. GASPARY, F.

1950 Investigaciones Arqueológicas y Antropológicas en un Cerrito de la Isla Los Marinos (Pcia. de Entre Ríos). Publicación del Instituto de Arqueología, Lingüistica y Folklore 23:3-66.

GONZÁLEZ DE BONAVERI, M.I.; FRÈRE, M. M.

2002 Explorando algunos usos prehispánicos de la alfarería pampeana. En: Mazzanti, D.; Berón, M.; Oliva, F. (Eds.) Del Mar a los Salitrales diez Mil Años de Historia Pampeana en el umbral del Tercer Milenio. Mar del Plata, Universidad Nacional de Mar del Plata Facultad de Humanidades Laboratorio de Arqueología, SAA:31-40.

HALLY, D. J.

1983 Use alteration of pottery vessel surfaces: an important source of evidence for the identification of vessel function. North American Archaeologist 4 (1):3-26.

HALLY, D. J.

1986 The Identification of Vessel Function: A Case Study from Northwest Georgia. American Antiquity 51(2):267-295.

HILBERT, K.

1992 Archäologische hinweise zum gebrauch von halluzinogenen schnupfdrogen in der Marajoara-Kultur, unterer Amazonas. Baessler-Archiv. Beiträge zur völkerkunde. Neue Folge, Band XL: 197-220.

HOLST, I. MORENO J. E.; PIPERNO, D. R.

2007 Identification of teosinte, maize, and Tripsacum in Mesoamerica by using pollen, starch grains and phytoliths. PNAS 104:17608-17613.

HORROCKS, M.

2005 A combined procedure for recovering phytoliths and starch residues from soils, sedimentary deposits and similar materials. Journal of Archaeological Science 32:1169-1175.
IPCNWG

2005 International Code for Phytolith Nomenclature 1.0. Annals of Botany 96 (2): 253-260; doi: 10.1093/aob/mci172.

ICSN

2011 The International Code for Starch Nomenclature. http://www.fossilfarm.org/ ICSN/Code.html (consulta 30- IX- 2011).

KOBAYASHI, $\mathrm{M}$.

1994 Use-Alteration Analysis of Kalinga Pottery: Interior Carbon Deposits of Cooking Pots. En: Longacre, W. A.; Skibo, J. M. (Eds.) Kalinga Ethnoarchaeology: Expanding Archaeological Method and Theory. Washington, DC, Smithsonian Institution Press:127-168.

KONDO, R.; CHILDS, C.; ATKINSON, I.

1994 Opal phytoliths of New Zealand. New Zeland, Maanaki Whenua Press.

KORSTANJE, M. A.; CUENYA, P.

2008 Arqueología de la agricultura: suelos y microfósiles en campos de cultivo del Valle del Bolsón, Catamarca, Argentina. En: Korstanje , M. A.; Babot, M. del P. (Eds.) Matices Interdisciplinarios en Estudios Fitolíticos y de Otros Microfósiles. BAR International Series 1870:133- 148.

KORSTANJE, M. A.; BABOT, M. DEL P.

2007 Microfossils characterization from south Andean economic plants. En: Madella, M.; Zurro, D. (Eds.) Plants, people and places. Recent studies in phytolith analysis. Oxbow books:41-72.

LAHITTE, H. B.; HURRELL, J. A.

1997 Plantas de la Costa. Buenos Aires, Editorial Literature of Latin America.

LOTHROP, S. K.

1956 Peruvian Pacchas and Keros. American Antiquity 21(3):233-24.

MARTÍNEZ, G.; MAZZANTI, D.; QUINTANA, C.; ZUCOL, A. F.; COLOBIG, M. M.; HASSAN, G.; BREA M.; PASSEGGI, E.

2011 Geoarchaeological and paleoenvironmental context of the human settlement in the eastern Tandilia range, Argentina. Quaternary International. En prensa.

MAZZIA, N.

2010-2011 Lugares y paisajes de cazadores recolectores en la pampa bonaerense: cambios y continuidades durante el Pleistoceno final- Holoceno. Tesis doctoral inédita. Facultad de Ciencias Naturales y Museo, Universidad Nacional de La Plata. Argentina. 
MAZZIA, N.

2012 Cueva Zoro: nuevas evidencias sobre pobladores tempranos en el sector centro oriental de Tandilla. Intersecciones en Antropología. En Prensa.

MEJIA, K.; RENGIFO, E.

2000 Plantas Medicinales de Uso Popular en la Amazonía Peruana. Lima, Editorial Tarea Asociación Gráfica Educativa.

MEGGERS, B. J.; EVANS, C.

1957 Archaeological Investigations at the Mouth of the Amazon. Washington, Smithsonian Institution, Bureau of American Ethnology, Bulletin 167: 1-664.

MENACHO, $\mathrm{K}$.

2007 Etnoarqueología y estudios sobre funcionalidad cerámica: aportes a partir de un caso de estudio. Intersecciones en Antropología 8:149-161.

MUÑOZ OVALLE, I. R.

2001 Uso de plantas en rituales funerarios del período Formativo en Arica. Chungara 33(1):155-160.

PALMATARY, H. C.

1949 The Pottery of Marajó Island, Brazil. Transactions of the American Philosophical Society 39(3):261-470.

PEARSALL, D. M.; CHANDLER-EZELL, K.; ZEIDLER, J. A.

2004 Maize in ancient Ecuador: results of residue analysis of stone tools from the Real Alto site. Journal of Archaeological Science 31:423-442

PIPERNO, D. R.

1988 Phytolith analysis: an archaeological and geological perspective. San Diego, Academic Press.

POLITIS, G.; BONOMO, M.

2012 Acerca de la entidad arqueológica Goya-Malabrigo (cuenca inferior del paraná) y su filiación arawak. Revista de la SAB. En prensa.

RICE, P. M.

1987 Pottery Analysis: A Sourcebook. Chicago, University of Chicago Press.

ROBINSON, D.; CALVO REBOLLAR, M.; SEVILLANO CALVO, E.

1991 Bioquímica y valor nutritivo de los alimentos. España, Editorial Acribia.

ROOSEVELT, A. C.

1991 Moundbuilders of the Amazon: geophysical archaeology on Marajó Island Brazil. San Diego, Academic Press.
ROTTLÄNDER, R. C. A.

1990 Lipid analysis in the identification of vessel contents. MASCA Research papers in Science and Archaeology 7:37-40.

SCHAAN, D. P.

1996 A linguagem iconográfica da cerâmica Marajoara. Dissertação de Mestrado, Pontifícia Universidade Católica do Rio Grande do Sul. Porto Alegre.

SERRANO, A.

1934 Noticia sobre un paradero indígena de la margen izquierda del arroyo Las Conchas (Departamento Paraná, Entre Ríos). Actas y Trabajos Científicos del XXV Congreso Internacional de Americanistas (La Plata 1934): 165-172.

SERRANO, A.

1950 Los primitivos habitantes de Entre Ríos. Paraná, Biblioteca Entrerriana "General Perón”, Ministerio de Educación, Provincia de Entre Ríos.

SANCHEZ, J. O., COLOBIG, M. M.; ZUCOL, A. F.

2011 Análisis fitolíticos del sitio Los Tres Cerros 1, Isla Las Moras (Victoria, Entre Ríos). Primeros Resultados. VI Congreso de Arqueología de la Región Pampeana Argentina:123. La Plata.

SCHULTES, R.E.

1976 Hallucinogenic plants. New York, Golden Press.

SKIBO, J. M.

1992 Pottery Function: A Use Alteration Perspective. New York, Plenum Press.

SKIBO, J. M.; M. DEAL

1995 Pottery function and organic residue: an appraisal. Conference on archaeology in South East Asia. University Museum and Art Gallery, Hong Kong:321-330.

TORRENCE, R.

2006 Starch and Archaeology. En: Torrence, R.; Barton, H. (Eds.) Ancient Starch Research. California, Left Coast Press:17-33.

TWISS, P. C.

1992 Predicted world distribution of C3 and C4 grass phytoliths. En: Rapp, G. Jr.; Mulholland, S. C. (Eds.) Phytoliths Systematics. Emerging Issues. Advances in Archaelogical and Museum Science 1:113-128.

TWISS, P. C.; SUESS, E. Y SMITH, R.

1969 Morphological classification of grass phytoliths. Soil Science Society of America. Proceedings 33(1):109-115.

U.S. TESTING COMPANY, INC.

Chemical and physical tables. Tables and Data. New Jersey, HOBOKEN:28-29. 
Análisis de residuos orgánicos y microfósiles silíceos de la "cuchara" de cerámica del sitio arqueológico Cerro Tapera Vázquez (Parque Nacional Pre-Delta, Argentina)

R. Museu Arq. Etn., São Paulo, n. 22: 31-50, 2012.

WASSÉN, S. H.

1965 The use of some specific kinds of South American Indian snuff and related paraphernalia. Etnologiska Studier 28:1-132.

YANG, X.; JIANG, L.

2010 Starch grain analysis reveals ancient diet at Kuahuqiao site, Zhejiang Province. Chinese Science Bulletin 55(12):1150- 1156.

ZUCOL, A. F.

1996 Estudios morfológicos comparativos de especies de los géneros Stipa, Panicum y Paspalum (Poaceae), de la Provincia de Entre Ríos. Tesis doctoral inédita, Universidad Nacional de La Plata. Argentina.

ZUCOL, A. F.; BONOMO, M

2008 Estudios arqueobotánicos en el sitio Nutria Mansa 1 (Partido de General Alvarado, Provincia de Buenos Aires): II. Análisis fitolíticos comparativos de artefactos de molienda. En: Korstanjey, M. A.; Babot, M. del P. (Eds.) Matices interdisciplinarios en Estudios Fitolíticos y de otros Microfósiles. BAR International Series 1870:173-185.

ZUCOL, A.F, COLOBIG, M. M.; MAZZANTI, D. L.

2007 Análisis de micro-restos en muestras sedimentarias del sitio 2 de la localidad arqueológica Amalia, provincia de Buenos
Aires (Argentina). XVI Congreso Nacional de Arqueología Argentina, I:141-147.

ZUCOL, A. F., BREA, M.; MAZZANTI, D. L.

2008 Análisis de restos orgánicos presentes en cerámicas arqueológicas de las Sierras de Tandilia (Provincia de Buenos Aires, Argentina). En: Korstanje, M. A.; Babot, M. del P. (Eds.) Matices Interdisciplinarios en Estudios Fitoliticos y de Otros Microfósiles. BAR International Series 1870:201- 208.

ZUCOL, A. F., PASSEGGI, E., BREA, M., PATTERER, N. I., FERNÁNDEZ PEPI, M. G.; COLOBIG, M. M. 2010 Phytolith analysis for the Potrok Aike Lake Drilling Project: Sample treatment protocols for the PASADO Microfossil Manual. En: Corbella, H.; Maidana, N. (Eds.) $1^{a}$ Reunión Internodos del Proyecto Interdisciplinario Patagonia Austral y 1er Workshop Argentino del Proyecto Potrok Aike Maar Lake Sediment Archive Drilling Project. Proyecto Editorial PIPA. Buenos Aires, Argentina. Programas y Resúmenes:81-84. ZUCOL, A. F., FIGUEROA, G.; M. M. COLOBIG

2012 Estudio de microrrestos silíceos en sistemas de aterrazamiento del primer milenio d.C. en el Valle de Ambato (Andes del sur), Catamarca, Argentina. Intersecciones en Antropología 13. En prensa. 